\title{
A PRÁTICA COMPARATISTA EM O FALSO MENTIROSO: MEMÓRIAS, DE SILVIANO SANTIAGO
}

\author{
Gabriela Perizzolo*
}

RESUMO: The objective of this paper is to study some of the Silviano Santiago's critical essays - those ones where ideas related to the comparative activity is discussed - establishing a relation with his novel O falso mentiroso: memórias. Trough out this parallel, we intend to emphasize a very important aspect considered by Comparative Literature: the value of the differences.

PALAVRAS-CHAVE: Literatura Comparada. Diferença. Outro. Identidade. Centro. Periferia.

Sabe-se que Silviano Santiago está entre os escritores-críticos brasileiros mais importantes da atualidade. Autor de obras como Uma literatura nos trópicos, publicada pela primeira vez no ano de 1978 e, Vale quanto pesa, em 1982, que reúnem ensaios e artigos essenciais para a literatura brasileira, Silviano Santiago também deve ser lembrado pelos romances com os quais presenteia o leitor - não somente o brasileiro, mas também aqueles que estão além das fronteiras do seu país de origem. Entre eles é necessário destacar Em liberdade (1981), Stella Manhattan (1985), Uma história de família (1992), Viagem ao México (1995) e, por fim, O falso mentiroso: memórias (2004), romance eleito para dar conta da tarefa de relacionar a posição do escritor - no que diz respeito à pratica comparatista - exposta em seus ensaios críticos e sua atividade prática, revelada através de sua produção supostamente ficcional.

\section{CONCEITOS E IDÉIAS TEÓRICO-CRÍTICAS}

Conforme já mencionado anteriormente, o propósito deste estudo é identificar conceitos e idéias relacionadas à prática comparatista na obra teórico-crítica de Silviano Santiago, e, posteriormente, pensá-las com relação ao romance $O$ falso mentiroso: memórias. Assim sendo, nesta etapa inicial far-se-á um levantamento das idéias e pensamentos de Santiago em alguns de seus textos teórico-críticos, dando ênfase às idéias compatíveis com a prática comparatista.

Para o cumprimento da tarefa proposta, foram escolhidos alguns textos do escritor, a saber: "O entre-lugar do discurso latino-americano", ensaio que faz parte da obra Uma literatura nos trópicos ${ }^{i}$, "Apesar de dependente, universal", texto que integra a obra Vale quanto pesa e, por fim, o artigo "Crítica cultural, crítica literária: desafios do fim do século", publicado na Revista Iberoamericana, no ano de 1997.

Silviano Santiago, em seu ensaio "O entre-lugar do discurso latino-americano", discute o lugar que o discurso literário latino-americano ocupa hoje no confronto com o europeu. Para desenvolver seu pensamento, o escritor faz uma retrospectiva histórica, mencionando alguns aspectos da colonização do território latinoamericano, mostrando a evidência do poder do colonizador - europeu - sobre o colonizado - indígena. Apresenta, então, o par binário colonizador/colonizado, no qual o primeiro elemento é carregado de positividade e de plenitude, enquanto, o segundo, é caracterizado pela falta/ausência/negatividade. O colonizador é pleno, absoluto e único. O povo colonizado é visto como o "outro", que deve adequar-se às imposições do colonizador:

[...] a vitória do branco no Novo Mundo se deve menos a razões de caráter cultural do que ao uso arbitrário da violência e à imposição brutal de uma ideologia, como atestaria a recorrência das palavras "escravo" e "animal" nos escritos dos portugueses e espanhóis (SANTIAGO, 2000, p. 11).

Silviano Santiago mostra que o colonizador não poupa esforços para promover e impor a língua portuguesa e a religião cristã entre os selvagens. Com isso, a supremacia da nação européia mantém-se intacta e cada vez mais valorizada:

Evitar o bilingüismo significa evitar o pluralismo religioso e significa também impor o poder colonialista. Na álgebra do conquistador, a unidade é a única medida que conta. Um só Deus, o verdadeiro Rei, a verdadeira Língua (SANTIAGO, 2000, p. 14).

O povo latino-americano passa, então, a vestir uma roupagem que não é sua. Vê-se obrigado a pensar e agir conforme os moldes europeus, atitude que provoca o apagamento das suas próprias origens. O colonizado passa a exercer um papel que não é seu, mas sim aquele imposto pelo colonizador.

Apesar desta força opressora exercida pelo europeu sobre o povo latino-americano, Silviano Santiago enfatiza que, com o passar do tempo, a América Latina teve papel importante na tarefa de mudar os rumos dessa história: "A maior contribuição da América Latina para a cultura ocidental vem da destruição sistemática dos

\footnotetext{
* Gabriela Perizzolo é mestranda em Literatura Comparada pela Universidade Federal do Rio Grande do Sul.
} 
conceitos de unidade e de pureza" (SANTIAGO, 2000, p. 16). Contrária às aspirações do europeu, a miscigenação dá-se não somente entre as pessoas, mas também, entre as línguas, entre as religiões e, acima de tudo, entre as formas de pensar.

Esta é a primeira grande questão que vai direto ao encontro das idéias sobre as quais muito se tem refletido e que envolvem a prática comparatista: a visão do outro, no caso a literatura latino-americana, como alguém menor, inferior e menos capaz. Este pensamento, na visão do comparatista atual (Silviano Santiago está entre eles), cai por terra, uma vez que se busca o apagamento de fronteiras, com o intuito de valorizar, também, o nacional, o regional, o próprio e não somente o internacional, o universal e o alheio:

A América Latina institui seu lugar no mapa da civilização ocidental graças ao movimento de desvio da norma, ativo e destruidor, que transfigura os elementos feitos e imutáveis que os europeus exportavam para o Novo Mundo (SANTIAGO, 2000, p. 16).

A partir desta necessidade de valorizar o que é próprio, Silviano Santiago propõe que se promova a um primeiro plano as diferenças, deixando de lado a prática binária que busca apenas o estudo das fontes e influências. Silviano Santiago deixa transparecer seu descontentamento com tal exercício, que, segundo ele, "se enraizou profundamente no sistema universitário" (SANTIAGO, 2000, p. 17). A partir desta recusa, Santiago traz à tona a discussão sobre intertextualidade. Tania Franco Carvalhal, em sua obra Literatura Comparada (2001, p. 50), acentua que tal conceito, cunhado por Julia Kristeva em 1969, foi estabelecido "para designar o processo de produtividade do texto literário, pois todo texto é absorção e transformação de outro texto". Para que as diferenças entre uma nação e outra, entre uma literatura e outra se sobressaiam é imprescindível que haja uma agressão ao modelo. Assim sendo, o escritor re-escreve o texto, introduzindo marcas que são próprias da sua escritura e da sua cultura. Segundo Silviano Santiago (2000, p. 20), "o segundo texto se organiza a partir de uma meditação silenciosa e traiçoeira sobre o primeiro texto [...]". Desta forma, propondo a desmistificação do texto único através da desarticulação e rearticulação do mesmo, o crítico situa o discurso latino-americano num entrelugar. Sandra Nitrini, comparatista contemporânea, ao discutir o posicionamento do crítico mineiro, no texto que ora está em estudo, ressalta o conceito dado por Santiago como sendo, o entre-lugar, o espaço

entre o momento da assimilação, apropriação, submissão e o exercício da agressão, destruição e subversão da cultura imposta, distinguindo-se, assim, da outra e opondo-se ao conceito de unidade cultural (NITRINI, 2000, p. 213).

Mais uma vez, Santiago aborda um tema nevrálgico da prática comparatista, que é a questão do entrelugar e, por conseqüência, das zonas de fronteira, margens e periferia. Neste interstício, "os vários particularismos não estariam em posição antagônica entre si, mas coexistiriam na totalidade criada" (CARVALHAL, 2003, p. 60). Este pensamento remete este estudo à mais um aspecto relevante no espectro das discussões comparatistas e que se encontra nas entrelinhas do texto de Santiago, que é aquele relacionado à busca de uma identidade própria:

a identidade se constrói como um sistema complexo e elaborado de relações com outros grupos, e essas relações são reguladas por normas e princípios que transcendem os particularismos e são universais (CARVALHAL, 2003, p. 61).

Quando o crítico afirma que

entre o sacrifício e o jogo, entre a prisão e a transgressão, entre a submissão ao código e a agressão, entre a obediência e a rebelião, entre a assimilação e a expressão - ali, nesse lugar aparentemente vazio [...] se realiza o ritual antropofágico da literatura latino-americana (SANTIAGO, 2000, p. 26)

está ratificando a existência de um lugar onde a voz que provém das margens pode estabelecer uma identidade própria e que, desta forma, com uma expressão agora também própria, esta voz poderá ser ouvida e respeitada.

No ensaio intitulado “Apesar de dependente universal”, escrito em 1980 e publicado dois anos mais tarde, na obra Vale quanto pesa, Silviano Santiago, com um tom bastante crítico, volta a fazer uma retomada histórica para refletir sobre temas como etnocentrismo, imitação e dependência cultural. Segundo ele:

Dentro dessa perspectiva etnocêntrica, a experiência da colonização é basicamente uma operação narcísica, em que o outro é assimilado à imagem refletida do conquistador, confundido com ela, perdendo portanto a condição única da sua alteridade. Ou melhor: perde a sua verdadeira alteridade (a de ser outro, diferente) e ganha uma alteridade fictícia (a de ser imagem refletida do europeu) (SANTIAGO, 1982, p. 15-6).

Silviano Santiago é tenaz ao discutir o processo de uniformização das culturas e enfatiza que é imprescindível que as civilizações situadas nas margens, entre elas o Brasil, lutem por seu espaço dentro do universo literário mundial. Segundo ele, é neste espaço situado entre o positivo e o negativo, que repousa a possibilidade de reafirmação cultural de países como, por exemplo, os latino-americanos: "Comparada às grandes, a nossa literatura é pobre e fraca. Mas é ela, não outra, que nos exprime" (CANDIDO apud SANTIAGO, 1982, p. 20). Nesse mesmo ensaio, o crítico vai mais além e enfatiza a necessidade de se reconhecer que, acreditar numa literatura desprovida de qualquer contato com culturas que se afirmam dominantes é "devaneio verde-amarelo" (SANTIAGO, 1982, p. 20). O que se deseja é um comportamento que seja, apesar de dependente, universal, ou ainda, que países como os latino-americanos produzam obras que ultrapassem os modelos e deixem transparecer seus traços realmente originais, dando ênfase às diferenças que se 
apresentam entre as mais variadas culturas. Sandra Nitrini reafirma esta idéia transcrevendo o pensamento de Santiago, o qual deixa claro que

a perspectiva correta para os estudos das literaturas latino-americanas é a literatura comparada e que, é impossível crer que o pensamento latino-americano possa ser autóctone [...] (SANTIAGO apud NITRINI, 2000, p. 212).

No ensaio intitulado "Crítica cultural, crítica literária: desafios do fim de século" (1997), Santiago retoma, entre outras, a questão da importância em ressaltar as diferenças entre as culturas. Através de um exemplo bastante esclarecedor, na medida em que utiliza a música popular brasileira para enfatizar o valor do Brasil, o crítico afirma que:

em lugar de separar e isolar vivências e experiências, em lugar de introjetar o rebaixamento cultural que lhe é imposto para se afirmar pelo ressentimento dos excluídos, a música popular passa a ser o espaço "nobre", onde se articulam, são avaliadas e interpretadas as contradições sócio-econômicas e culturais do país, dandonos o seu mais fiel retrato (SANTIAGO, 1997, p. 371).

O que a Literatura Comparada busca e que Silviano Santiago destaca em seu texto é uma postura, por parte da literatura latino-americana, que seja - apesar de ainda, em parte, dependente -universal e, a forma que o crítico sugere para o alcance deste posicionamento no cenário global se dá através da valorização das diferenças.

\section{O ENREDO}

Antes de iniciar a abordagem que diz respeito ao enredo do romance, cabe mencionar algumas palavras, do próprio escritor, sobre o título do livro, a fim de estabelecer relação com o conteúdo do romance. Na contracapa da obra, Silviano Santiago transcreve a seguinte passagem da Enciclopédia Mirador:

O falso mentiroso: paradoxo atribuído a Euclides de Mileto (século IV a.C.), cuja forma mais simples é: se alguém afirma "eu minto", e o que diz é verdade, a afirmação é falsa; e se o que diz é falso, a afirmação é verdadeira e, por isso, novamente falsa etc. (SANTIAGO, 2004).

Segundo Silviano Santiago, o paradoxo do falso mentiroso é

a melhor tradução do que deve ser o papel e a função da literatura. O que é literatura? É um texto 'mentiroso', uma ficção que não apreende de maneira direta o real, mas que, nos melhores casos, contém a verdade (SANTIAGO, em entrevista a SEREZA, 2004, p. 10).

Após tomar conhecimento das idéias do escritor acima expostas, pode-se verificar que Silviano Santiago deseja contemplar o leitor com uma obra que, apesar de ficcional, possui algo de verossímil e, segundo ele, esta é a literatura de boa qualidade. É com base nesse conceito de literatura que Silviano Santiago dá vasão à tessitura de sua obra. Para escrever as memórias de Samuel, protagonista do romance, Santiago utiliza um vocabulário grotesco e um linguajar desbocado. Desta forma, se por um lado o escritor aproxima-se da linguagem popular, por outro, distancia-se da literatura reflexiva. Segundo Santiago, em entrevista à Revista Cult (2003), o livro só fica mais reflexivo a partir do nono capítulo. Para o escritor, a obra literária precisa ser reflexiva, se não o é, acaba por se configurar em um outro objeto, que Santiago não consegue ainda definir. Por pensar desta forma, a todo o momento, Silviano Santiago, através das palavras de Samuel, seu narrador-personagem, faz uso de metáforas. $\mathrm{O}$ escritor as utiliza com o intuito de promover a reflexão do leitor. Exemplo de provocação deste exercício reflexivo é a grande metáfora do romance, a saber, "camisa-de-vênus" para designar a segunda metade do século vinte. Segundo Santiago, "a expressão é chula, incomoda, mas é uma metáfora competente" (SANTIAGO, em entrevista a SEREZA, 2004, p. 12). O escritor afirma ainda que a reconhece eficaz, pois "serve para configurar um século que saiu para ser revolucionário e acabou sendo profilático. O século vinte foi mais malthusiano do que revolucionário" (SANTIAGO, em entrevista a SEREZA, 2004, p. 12).

No romance, composto de quatorze capítulos, Samuel Souza Aguiar, aos sessenta e seis anos de idade, relata de forma picaresca e divertida, os percalços por ele sofridos desde seu nascimento até os dias atuais. Artista plástico, Samuel mora no Rio de Janeiro com seus dois filhos e com sua esposa surda-muda, Esmeralda. O relato das memórias tem início com a seguinte afirmação:

Não tive mãe. Não me lembro da cara dela. Não conheci meu pai. Também não me lembro da cara dele. Não me mostraram foto dos dois. Não sei o nome de cada um. Ninguém quis me descrevê-los com palavras. Também não pedi a ninguém que me dissesse como eram. Adivinho. Posso estar mentindo. Posso estar dizendo a verdade (SANTIAGO, 2004, p. 9).

Samuel desconhece seus progenitores verdadeiros e, por isso, não sabe quem é realmente. Na tentativa de desvelar a verdade sobre o que ocorreu no dia de seu nascimento, o narrador levanta várias hipóteses e reflete sobre cada uma delas, com o intuito de conhecer melhor a si mesmo, bem como, com o objetivo de tentar compreender a vida intrincada que o destino lhe reservou. No decorrer do romance, Samuel descobre que o casal, que se diz ser seu pai e sua mãe, o sequiestrou na maternidade. De posse desta informação, o narrador fica ainda mais confuso e, em meio ao relato de suas histórias de infância, deixa transparecer o desejo de buscar sua própria identidade. Neste esforço, no sentido de desvendar seu passado, Samuel expõe a vida de seus pais, em especial, as trapalhadas do doutor Eucanaã, seu falso pai - assim Samuel o designa -, o qual vive um casamento de aparências, julga-se pai de um filho que não é seu e, para completar, esconde a verdadeira fonte de sustento da 
família. Dizendo-se advogado com escritório montado no centro da cidade do Rio de Janeiro, o doutor Eucanaã mantém paralelamente uma fábrica de camisas-de-vênus, aparato necessário na época para combater doenças, como a sífilis, e também, para evitar filhos fora do casamento:

Papai, o falso, era advogado de profissão. Com banca montada no centro da cidade. Em edifício da avenida Rio Branco, quase esquina da rua do Ouvidor. Quem subisse até o sexto andar do prédio, tocasse a campainha e fosse convidado pela Teresa a entrar, dava com a sala de espera, onde ela e telefone tomavam assento. Transposta a porta interna, encontraria escritório bem instalado e toalete privativos (SANTIAGO, 2004, p. 66).

Advogado pra inglês e pra família ver. Nunca pisou no foro. Pelo menos depois de formado. A verdadeira e volumosa fonte de renda da família ficava a descoberto num misterioso e fidalgo retrato [...] (SANTIAGO, 2004, p. 77-8).

Eucanaã mantém dependurado na parede de seu escritório de advocacia dois retratos, os quais carregam a figura dos responsáveis pelo seu sucesso como empresário: o de Thomas Robert Malthus, economista e pastor anglicano, o qual lançou o brado de alerta contra a pobreza crescente da humanidade e a fome permanente dos homens e o de Gabriel Falópio, anatomista italiano: "Trazia o destino no próprio nome. Às claras. Estampado nas quatro primeiras letras do sobrenome, f-a-l-o [...]” (SANTIAGO, 2004, p. 79). Dr. Eucanaã e Falópio, segundo as palavras de Samuel, "comungavam ideais secretos". Samuel enfatiza que

Falópio era o patrono dos seus negócios escusos e de alta rentabilidade. Com o beneplácito dele montou uma indústria legitimamente brasileira, ergueu um império internacional e sustentou o alto padrão de vida dos Souza Aguiar (SANTIAGO, 2004, p. 84).

Envergonhado por obter seu sustento através de negócio tão impudico, a seu ver e também aos olhos da sociedade da época, doutor Eucanaã mantém a sete chaves o segredo que envolve sua fábrica de camisa-devênus Cacique. O leitor fica sabendo da tal indústria, também, através das palavras de Samuel: "Papai fabricava e vendia no atacado - entre outros produtos de menor importância - preservativos masculinos, conhecidos como camisas-de-vênus" (SANTIAGO, 2004, p. 107). Toda esta falta de transparência na vida do pai, faz com que Samuel sinta-se confuso e, cada vez mais, desejoso de descobrir a verdade dos fatos que envolvem a sua família e, principalmente, que o envolvem. É neste ambiente circundado por uma atmosfera conturbada que Silviano Santiago situa sua personagem, Samuel, o qual, por não saber quem é realmente, em função do ocorrido na época de seu nascimento, sai em busca de sua identidade.

Silviano Santiago, através da personagem Samuel, descreve situações que exemplificam seu pensamento teórico acerca de algumas idéias comparatistas. Esta relação é conteúdo do item que se desenvolve a seguir.

\section{QUESTÕES RELACIONADAS À PRÁTICA COMPARATISTA NO ROMANCE}

Sendo esta a última etapa do estudo acerca das teorias comparatistas e a obra de Silviano Santiago, acentuar-se-ão algumas passagens do romance mais recente do escritor, $O$ falso mentiroso: memórias, expondo assim, as idéias e conceitos relacionados à prática comparatista, mencionados no início deste trabalho, agora postos em prática pelo escritor brasileiro.

O primeiro aspecto a ser levado em consideração é a pertinência de Silviano Santiago e sua produção literária ao contexto latino-americano. Brasileiro, latino-americano e, portanto, pertencente a uma cultura periférica, Santiago e seu romance fazem parte, se colocados em relação às culturas centrais, a européia, por exemplo, segundo seus apontamentos teóricos, de um grupo de minorias. O romance, O falso mentiroso, desta forma, é visto como voz que provém das margens. É esta visão que o crítico e os demais estudiosos de Literatura Comparada desejam mudar. Conforme mencionado anteriormente, Silviano Santiago propõe que este rótulo seja alterado, não através da inversão de posições, mas sim através da possibilidade de dar voz a quem, até então, esteve silenciado. Segundo ele, há que se levar em conta as diferenças entre as culturas. E, é exatamente isso que Silviano Santiago faz através da escritura d' $O$ falso mentiroso. O enredo é singular por natureza. O escritor trata de temas universais - por certo já examinados por outros autores - de forma original. Um exemplo disto são os seqüestros nas maternidades: Samuel, protagonista de uma situação de natureza semelhante, discorre sobre o tema - ao contrário do que se espera - com uma dose generosa de senso de humor. Esta é uma forma de Santiago mostrar o seu jeito de contar a história, que não é aquele já contado pela tradição. A originalidade de Santiago também se destaca por sua aproximação da linguagem popular, uma vez que utiliza o grotesco e o linguajar desbocado, distanciando-se da literatura reflexiva, de vocabulário abstrato, tida pelos padrões, como literatura erudita e, portanto, de melhor qualidade. Mas, o que é um texto de melhor qualidade? Será aquele imposto pela tradição? Segundo Maria Lúcia Aragão

os pesquisadores têm procurado rever, permanentemente, vários conceitos enraizados e tidos como definitivos, oferecendo novas respostas e novas possibilidades de enfrentar tabus arraigados no inconsciente coletivo. Tudo isso veio alargar, não só a compreensão do literário, mas veio também inaugurar um sistema de trocas enriquecedor (ARAGÃO, 1993, p. 56-7). 
É este sistema de trocas que Silviano Santiago defende e pratica através de sua escritura. Deseja mostrar que o escritor e sua obra, ambos provenientes das margens, têm muito a dizer e a apresentar ao universo literário e que seu discurso pode ser tão bom quanto àquele que provém dos grupos provenientes do centro.

A personagem criada por Santiago também é subversiva: Samuel é um indivíduo fora dos padrões, na medida em que é filho de dois loucos seqüestradores, casado com uma surda-muda cor de jambo (Esmeralda) e que, ao final de sua vida, torna-se um pintor plagiário. De que forma dá-se o desvio? Samuel é filho adotivo, mas foi seqüestrado, é casado, mas com uma surda-muda de cor, sua atividade profissional é de artista plástico, mas, ao invés de criar suas próprias telas, plagia obras de grandes pintores. As próprias palavras de Samuel atestam seu desvio com relação ao perfil padrão do indivíduo: "Nada trazia comigo. Nem chupeta nem chocalho. Devia ser silencioso e dócil. Já tinha comportamento coibido de enjeitado" (SANTIAGO, 2004, p. 44). A personagem afirma ainda: "Não nasci como a maioria. De graça. Por obra e efeito da fertilização natural. Custei os olhos da cara aos meus pais adotivos [...]. Nasci grosseiro e impertinente. Incapaz de selecionar a palavra adequada ao interlocutor e ao ambiente" (SANTIAGO, 2004, p. 45). Com efeito, Samuel é uma personagem que agride os modelos impostos pelos padrões tidos como aceitos, exatamente por ser calcado na diferença. Samuel é mais uma prova de que é possível pôr em prática idéias e conceitos comparatistas que visam a valorização da alteridade. Santiago, também está apontar a questão da cópia e da imitação. Será que Samuel plagia as obras ou as re-cria? "Na verdade, minha obra verdadeira e subterrânea começa no dia em que descobri como copiar Goeldi, sendo eu mesmo" (SANTIAGO, 2004, p. 184). Pode-se perceber que a personagem deixa transparecer a idéia de que, ao copiar as telas, imprime características pessoais, transformando a obra em um novo trabalho, único, seu. Mais uma vez, vê-se, na prática, idéias relacionadas à Literatura Comparada. Além dos traços pessoais, provavelmente, o fator temporal também altere o resultado final da nova obra: "Os textos são na aparência iguais, mas a face invisível deles, a que se revela pelo deslocamento temporal efetuado [...] modifica integralmente os significado" (CARVALHAL, 2001, p. 67). Assim sendo, é possível concluir que a personagem de Santiago reconstrói as telas, dando a elas uma reiterpretação própria.

Ainda na tentativa de apresentar a questão do duplo, da cópia e da imitação, idéias relacionadas à prática comparatista, através das quais, como já mencionado anteriormente, o artista é capaz de enfatizar as diferenças, Silviano Santiago cria uma personagem - Samuel - que nasce dentro dos moldes tradicionais e re-nasce, de forma incomum (na casa de seus pais seqüestradores):

Na minha certidão a data de nascimento não é a do meu nascimento. É a data da minha morte para os meus pais. Os verdadeiros. O dia do meu nascimento na certidão é o do meu renascimento na casa dos meus pais. Os falsos (SANTIAGO, 2004, p. 48).

Trata-se de uma cópia com uma história própria e original. Samuel re-escreve também sua história de vida e, nessa re-escritura, vê-se obrigado a criar também uma nova identidade:

Dezenove dias a mais, sai vencedora a cópia. Dezenove dias a menos, sai vencedor o original. Será que faz diferença? Por mais que me tranqüilizem, sei que faz. Faz diferença e muita. Ninguém volta impunemente do signo de Libra [...] para o signo de Virgem [...] Menos impunemente se arrebata alguém do signo de Virgem para jogá-lo no signo de libra (SANTIAGO, 2004, p. 49).

Outro aspecto da teoria comparatista que o escritor mineiro emprega nas entrelinhas de seu romance, trata-se da existência de um entre-lugar, que nada mais é que, conforme já abordado nos textos teóricos de Santiago, o lugar

no qual o terceiro, o excêntrico, o descentrado, nunca seja um terceiro 'excluído' da combinatória de possibilidades, mas uma parte constitutiva de seu movimento (CAMPOS apud CARVALHAL, 2003, p. 104).

É neste espaço que Silviano Santiago deseja que sua obra seja vista, afinal, sendo ele representante de uma nação colonizada, luta pela conquista de um espaço, onde seu discurso possa ser valorizado. Para tanto, posiciona a narrativa entre ficção e verdade, uma vez que conta histórias baseadas, em parte, na sua infância através de personagens fictícias, as quais são, também, representantes de culturas periféricas - Samuel e sua família são brasileiros - . Sendo o entre-lugar o espaço em que as culturas das margens passam a ter voz, é neste interstício que Santiago situa Samuel, pois ali a personagem possui a chance de fazer-se escutar.

Mais uma vez, o exercício da prática comparatista realiza-se no romance $O$ falso mentiroso. Silviano Santiago cria a personagem de doutor Eucanaã e o faz proprietário de uma rentosa fábrica de camisas-de-vênus. O produto é exportado, mas país importador não quer que sua procedência seja desvelada e exige do produtor, no caso, brasileiro, o apagamento da origem da mercadoria:

A liderança da indústria paterna no plano internacional nunca foi registrada nos anais. Disfarçada no Brasil pelo anonimato industrial. Anônima lá fora pelo silêncio em relação à procedência do produto. Exigiam que a caixinha de papelão, que guardava e protegia a camisinha, viesse sem dizeres. Extraviava-se a marca registrada. Valia o produto. [...] Sem indicação de procedência. Eis o destino de capitão da indústria brasileiro. Eis o destino do produto nosso (SANTIAGO, 2004, p. 118).

Como se pode verificar, através de situações agora de ordem econômica, Silviano Santiago, reitera, mais uma vez, a questão da supremacia de uma nação sobre outra. O colonizador impondo regras e o colonizado tendo que se submeter a essas regras. A Literatura Comparada vem lutando pela reversão deste quadro, dando oportunidade às minorias, através do descentramento do olhar, passando a dar ênfase ao diálogo transcultural. Segundo Eduardo Coutinho: 
Qualquer concepção monolítica da cultura latino-americana vem sendo hoje posta em xeque e muitas vezes substituída por propostas alternativas que busquem dar conta de seu caráter híbrido (COUTINHO, 1996, p. 73).

Santiago, neste exercício, no qual, pôde-se perceber, aplica várias idéias e conceitos comparatistas, busca, na realidade, defender, acima de tudo, a voz do outro, incentivando o diálogo entre as nações. Acredita-se que é substantivo para o crítico em questão propagar a idéia de que mesmo dependentes, as nações precisam exaltar suas diferenças, seus traços próprios e não permitir que suas origens sejam apagadas, pois é aí que está submerso valor de sua cultura e, consequientemente, de sua literatura.

\section{REFERÊNCIAS BIBLIOGRÁFICAS}

ARAGÃO, Maria Lúcia. A literatura comparada: histórico e perspectivas. Revista Tempo Brasileiro, p. 49-61, jul-dez. 1993.

CARVALHAL, Tania Franco. Literatura comparada. 4. ed. São Paulo: Ática, 2001. 94 p.

CARVALHAL, Tania Franco. O próprio e o alheio: ensaios de literatura comparada. 1. ed. São Leopoldo: UNISINOS, 2003. 264 p.

COUTINHO, Eduardo. Literatura comparada, literaturas nacionais e o questionamento do cânone. Revista Brasileira de Literatura Comparada, n. 3, p. 67-73, 1996.

SANTIAGO, Silviano. O falso mentiroso: memórias. 1. ed. Rio de Janeiro: Rocco, 2004. 222 p.

SANTIAGO, Silviano. Uma literatura nos trópicos. 2. ed. Rio de Janeiro: Rocco, 2000. 219 p.

SANTIAGO, Silviano. Vale quanto pesa. 1. ed. Rio de Janeiro: Paz e Terra, 1982. 200 p.

SANTIAGO, Silviano. Crítica cultural, crítica literária: desafios do fim do século. Revista Iberoamericana, v. LXIII, n. 180, p. 363-377, jul-set. 1997.

SEREZA, Haroldo Ceravolo. A absoluta perfeição do crime. Revista Cult, São Paulo, n.81, p. 8-12, jun. 2004. NITRINI, Sandra. Literatura comparada. 2. ed. São Paulo: EDUSP, 2000. 300 p.

Notas:

\footnotetext{
${ }^{\mathrm{i}} \mathrm{O}$ ano de publicação da primeira edição desta obra é 1978. Neste estudo, porém, faz-se referência à $2^{\mathrm{a}}$ edição do livro, publicada no ano 2000.

ii Segundo o Dicionário Eletrônico Houaiss da Língua Portuguesa 1.0, o termo malthusiano pode ser definido da seguinte forma: adepto ou seguidor das idéias de Thomas Malthus (1766-1834) ou do malthusianismo. Doutrina de Malthus (1766-1834), economista e demógrafo inglês, que exorta à prática da continência sexual voluntária, invocando a disparidade entre o crescimento demográfico e a produção de alimentos.
} 